\title{
A quality improvement project to reduce intravenous catheter related infections in the neonatology unit of Kibogora hospital in Rwanda
}

Jean Paul Nsengiyumva ${ }^{1}$, Rex Wong*2, Eva Adomako ${ }^{2}$, Victor Pawelzik ${ }^{2}$, Julie Yerger ${ }^{1}$, Euphrosine Uwitonze ${ }^{1}$, Damien Nsabimana ${ }^{1}$, Sheila Etherngton ${ }^{1}$, Dariya Mukamusoni ${ }^{3}$, Laetitia Nyirazinyoye ${ }^{4}$

${ }^{1}$ Kibogora Hospital, Rwanda

${ }^{2}$ Yale Global Health Leadership Institute, Yale University, United States

${ }^{3}$ Kibogora Polytechnic University, Rwanda

${ }^{4}$ School of Public Health, University of Rwanda, Rwanda

Received: June 30, 2016

DOI: $10.5430 /$ jha.v5n5p60
Accepted: July 19, 2016

Online Published: July 22, 2016

\begin{abstract}
In developing countries, intravenous (IV) catheter related infections (CRI) rate is generally high. Neonates are more susceptible to develop CRI. We examined the impact of a quality improvement project on IV CRI rates in the neonatal intensive care unit (NICU) of a district hospital in Rwanda. A pre- and post-intervention study was conducted from 2014 to 2016 to evaluate the IV CRI rate and nurses' IV management technique. A written test was administered to evaluate their knowledge on the matter. The intervention had three components: First implementing an IV management policy. Secondly, training staff on the policy and finally, managers provided support and supervision during the change. We measured five indicators: (1) the IV CRI rate; (2) the percentage of nurses who tested $\geq 80 \%$ on IV management knowledge; (3) the percentage of IV devices changed following the World Health Organization (WHO) guideline; (4) IV management technique; and (5) the hospital length of stay (LOS). The IV CRI rate reduced from $32.1 \%$ to $14.5 \%(p<.001)$. The hospital LOS reduced from 15.31 to 7.43 days $(p<.001)$. The compliance of changing IV following WHO guideline increased from $0 \%$ to $99 \%(p<.001)$; proper IV management technique use increased from $43 \%$ to $96 \%(p<.001)$; the mean rank of staff on IV management knowledge score significantly increased from 3.5 to $9.5(p=.004)$. This project demonstrates that a quality improvement project can help address the IV CRI at very low cost in a resource-challenged setting.
\end{abstract}

Key Words: Intravenous catheter related infection, Hospital acquired infection, Low income country, Quality improvement

\section{INTRODUCTION}

Intravenous (IV) therapy is an indispensable part of clinical care used in a wide variety of healthcare settings. ${ }^{[1-4]} \mathrm{In}$ travascular catheterization involves using a needle to insert through the skin and into the blood vessel. ${ }^{[5]}$ The variety of procedures that requires IV catheterization has increased significantly with the advance in medical technology. IV therapy can be used for correcting electrolyte imbalances, delivering medications, blood transfusion, fluid replacement, or chemotherapy. ${ }^{[6,7]}$ The IV route is also the fastest way to deliver fluids and medications throughout the body; IV therapy has $100 \%$ medication bioavailability. ${ }^{[8]}$

Despite IV catheterization being an essential life-saving med-

*Correspondence: Rex Wong; Email: rex.wong@ yale.edu; Address: Yale Global Health Leadership Institute, Yale University, United States. 
ical intervention, the use of IV catheters has been associated with catheter related infections (CRI). ${ }^{[5,7-9]}$ IV CRI can cause serious illness and disabilities, longer length of stay (LOS), higher health expenses and even death. ${ }^{[1,2]}$ Studies have indicated the rates of CRI ranged from 6.4 to 8.3 episodes per 1,000 patient days in neonatal intensive care unit (NICU) in the United States of America; caused approximately 90,000 deaths and cost almost $\$ 4.5$ billion annually. ${ }^{[10-13]}$ The burden of CRIs in developing countries is more severe; with reported IV CRI rates varying from $4.5 \%$ to as high as to $38.1 \% .^{[14-17]}$

Many factors contribute to the risk of IV CRI. Neonates, with still developing immune systems, are more susceptible to develop CRI; particularly those who receive more invasive care. ${ }^{[16]}$ The potential risk for infection significantly increases when the IV catheter is left in situ for more than 3 to 7 days, ${ }^{[18-20]}$ or when left in place with no present therapeutic use (idle insertion). ${ }^{[20,21]}$ The skills and techniques used in inserting IV catheter also have an impact on IV CRIs. There is a positive correlation between the number of attempts to insert catheters and IV CRI rates. ${ }^{[22,23]}$ Study has shown that the chance of infection significantly increased from $35.3 \%$ to $88.9 \%$ when the number of attempts increased just from two to three. ${ }^{[22]}$ Studies have shown various forms of education, including training on IV catheter handling, dressing, hand hygiene and hub disinfection could improve the compliance of health care workers on IV catheter management and effectively decrease IV CRI rates. ${ }^{[24,25]}$

There have been an increasing number of hospital quality improvement efforts in Rwanda in the recent years offering specific examples of how these efforts have proved beneficial to the provision of basic care processes ${ }^{[26]}$ reducing waiting time, ${ }^{[27]}$ documentation compliance, ${ }^{[28]}$ and patient flow. ${ }^{[29]}$ However, few published studies related specifically to reducing IV CRI in Rwanda exist. Accordingly, we sought to examine the impact of a quality improvement project on IV CRI rates in the NICU of a district hospital in Rwanda. Findings from this study may be useful for other quality improvement initiatives in similar resource-limited NICU.

\section{METHOD}

\subsection{Setting}

Our study was conducted in the NICU of Kibogora District Hospital, where reports showed high IV CRI. The neonatology ward in the hospital has 10 beds, 6 incubators, 8 cribs, with an average occupancy rate of 104\%. In 2013, about $90 \%$ of the 490 babies admitted to the neonatology unit received IV procedures. Despite the high frequency of applying IV procedures, the neonatology unit had no standard guideline or policy to direct IV management practice before our inter- vention. Nurses' skills or practices were not monitored or supervised.

\subsection{Design and sample}

We conducted a pre- and post-intervention study to examine the impact of a quality improvement projects on the IV CRI rates in the neonatology unit in the hospital, the initial assessment was conducted from December 2014 to February 2015.

For the IV CRI rates, the pre-intervention baseline data was collected using a IV CRI data collection form adapted from World Health Organization (WHO) recommendation (see Table 1). ${ }^{[20]}$ Data was collected during three months from December 2014 to February 2015 and repeated from January to March 2016, one month after implementation. The preand post-intervention samples involved all babies in the unit with IV insertions during the study period. We have also collected the number of days patients stayed in the hospital for the same periods.

For the IV management knowledge of nurses, we administered a written test to all six nurses working in the neonatology unit. The test included 3 questions: (1) Define signs and symptoms of IV catheter related infection; (2) What are the 4 causes of IV catheter related infection? And (3) What are the appropriate time the catheter and related accessories needed to be changed?

For the competency of nursing in IV management, the head nurse conducted a 1-month observation study in June 2015 to see if proper aseptic techniques were used in the insertion and management of IV catheters. All IV related work activities by the nurses in the neonatology unit were observed during the one month study period. A competency checklist was used to collect and record information during the observation. There were 6 items on the checklist, this included: (1) Can the nurse find the vein in less than 2 attempts? (2) Conduct aseptic/proper IV management technique in the handling of needle when it is not in the catheter; (3) Conduct aseptic/proper IV management technique during weighing; (4) Conduct aseptic/proper IV management technique during changing clothes; (5) Conduct aseptic/proper IV management technique during changing perfusion; and (6) Conduct aseptic/proper IV management technique during giving medication. Each of the 6 items was considered as an opportunity and was measured against the actual performance.

For the IV management practice, we followed a cohort of patients in the unit between April and July 2015 and recorded the duration and frequency when their IV lines, bags and catheters were changed and compared to the WHO recommended standard. ${ }^{[17]}$ 
Table 1. Tools for data Collection IV Catheter infection

KIBOGORA HAI SURVEILLANCE CHECKLIST Surveyor Name:

\begin{tabular}{|l|l|l|}
\hline Date: & Patient ID No.: & Patient Initials: \\
\hline Unit Name: & Unit Specialty: & Bed No: \\
\hline
\end{tabular}

\section{PATIENT INFORMATION:}

\begin{tabular}{|l|l|l|c|}
\hline Date of Admission: & Age: & Weight: & Male \\
\hline Relevant Medical History: & \\
\hline Reason for Current Admission:
\end{tabular}

\section{RISK FACTORS FOR HOSPITAL ACQUIRED INFECTION (Check all that apply)}

\begin{tabular}{|l|l|l|l|l|l|l|l|}
\hline Risk Factors & & $\begin{array}{l}\text { Date 1 site } \\
\text { Inserted: }\end{array}$ & $\begin{array}{l}\text { Date 1 } \\
\text { Removed: }\end{array}$ & $\begin{array}{l}\text { Date 2 site } \\
\text { Inserted: }\end{array}$ & $\begin{array}{l}\text { Date 2 } \\
\text { Removed: }\end{array}$ & $\begin{array}{l}\text { Date 3 site } \\
\text { Inserted: }\end{array}$ & $\begin{array}{l}\text { Date 3 } \\
\text { Removed: }\end{array}$ \\
\hline HIV & No Yes & & & & & & \\
\hline Neonate & No Yes & & & & & & \\
\hline IV Catheter & No Yes & & & & & & \\
\hline
\end{tabular}

\begin{tabular}{|l|l|l|l|l|l|l|l|}
\hline Risk Factors & & $\begin{array}{l}\text { Date 4 site } \\
\text { Inserted: }\end{array}$ & $\begin{array}{l}\text { Date 4 } \\
\text { Removed: }\end{array}$ & $\begin{array}{l}\text { Date 5 site } \\
\text { Inserted: }\end{array}$ & $\begin{array}{l}\text { Date 5 } \\
\text { Removed: }\end{array}$ & $\begin{array}{l}\text { Date 6 site } \\
\text { Inserted: }\end{array}$ & $\begin{array}{l}\text { Date 6 } \\
\text { Removed: }\end{array}$ \\
\hline HIV & No Yes & & & & & & \\
\hline Neonate & No Yes & & & & & & \\
\hline IV Catheter & No Yes & & & & & & \\
\hline
\end{tabular}

CLINICAL FINDINGS (only check yes if findings started 48 hours after IV insertion)

\begin{tabular}{|l|c|l|}
\hline Findings & $\begin{array}{l}\text { Yes If Sign of } \\
\text { Infection }\end{array}$ & $\begin{array}{l}\text { Notes (You must check all that apply if there are signs of } \\
\text { infection that appear 48 hours or more after admission) }\end{array}$ \\
\hline $\begin{array}{l}\text { Temp }>38{ }^{\circ} \mathrm{C} \text { for }>24 \text { hours } \\
\text { Hypothermia }<36, \text { apnea, not feeding well }\end{array}$ & No Yes & Date started: \\
\hline $\begin{array}{l}\text { IV Catheter Infected (suspect) Previous IV site } \\
\text { infected }\end{array}$ & No Yes & $\begin{array}{l}\text { Redness at site } \\
\text { Pain to touch } \quad \text { Hocalized Swelling touch }\end{array}$ \\
\hline
\end{tabular}

\section{SUSPECT HAI?}

\begin{tabular}{|l|l|l|}
\hline Findings & & Notes \\
\hline IV catheter site infection & No $\quad$ Yes & \\
\hline Other infection: & No $\quad$ Yes & \\
\hline
\end{tabular}

\section{WHO 2002 DEFINITIONS OF HAI}

\begin{tabular}{|l|l|l|}
\hline Code & Type of Nosocomial Infection & Criteria \\
\hline \multirow{4}{*}{ VCI } & Vascular Catheter Infection & Shows any of the following symptoms: \\
& Umbilical venous catheter & (1) Inflammation \\
& & (2) Lymphangitis
\end{tabular}

\subsection{Intervention}

A project team was formed including the chief of nursing, physicians and nurses from the neonatology unit. The team following the Strategic Problem Solving (SPS) ${ }^{[30]}$ approach to design the quality improvement project. The SPS is a stepby-step process allowing the team to identify the problem, set objective, collect evidence and data to conduct root cause analysis, compare and select the best intervention among different alternative solutions, implement and evaluate the intervention. The intervention we selected to reduce IV CRI and improve IV management practice included three main areas: (1) establishing IV management guideline, (2) staff training, and (3) supportive supervision to help nursing staff to fully understand and implement the standard practice. 
The team consulted the physicians and nurses and developed the IV management policy and procedures for the neonatology unit based on the WHO guidelines. A series of staff trainings on the new IV management policy and procedures were organized. The training was a half-day session and was repeated 3 times to ensure all staff working in different shifts could participate. Printed handouts and training materials were provided to the unit and made available to all staff working in the unit. In order to ensure all nurses working in the neonatology unit understand the new practice and were fully supported, the chief of nursing provided supportive supervision two times a week during the initial implementation period. All nurses in the neonatology unit were being observed at least 2 times during the first month of implementation, and more if needed. The chief of nursing conducted one-on-one meetings with individual nurses to provide feedback on their performance. The new IV management policy and procedures were officially implemented in December 2015.

\subsection{Data and measures}

We measured and compared the pre- and post-intervention results of the following five indicators: (1) the IV CRI rate in the neonatology unit; (2) the percentage of nurses who had testing scores $\geq 80 \%$ on IV management knowledge; (3) the percentage of IV devices that were changed according to the WHO guideline; (4) IV management technique; and (5) the
LOS in hospital. We have also compared the LOS of patients with or without IV CRI.

\subsection{Data analysis}

Chi Square tests were used to compare the pre- and postintervention IV catheter infection rates, the percentages of IV devices that were changed according to the WHO guideline, and IV management technique. Fisher's Exact test was used to compare the pre- and post-intervention percentages of nurses who scored $80 \%$ or higher on IV management knowledge test due to smaller sample size. Two-independent sample $t$ tests were used to compare the pre- and post-intervention LOS as well as between patients with and without IV CRI. All data analysis were completed using SPSS v.17.0 statistical software at a significance level of $p \leq .05$.

\section{Results}

Out of 134 babies admitted with IV catheter in the pre intervention, a total of 43 (32.1\%) infections were found. A total of 30 infections were found out of 207 (14.5\%) babies admitted with IV catheters in the post intervention period. The IV CRI rate was significantly reduced from $32.1 \%$ in pre-intervention to $14.5 \%$ in post intervention, with $p<.001$. The average LOS reduced significantly from 15.31 days $(S D=5.39)$ pre-intervention to 7.43 days $(S D=3.80)$, with $p<.001$ (see Table 2).

Table 2. Summary of pre- and post-intervention results

\begin{tabular}{|c|c|c|c|c|}
\hline & Pre intervention & Post intervention & Change & $p$-value \\
\hline Babies with IV catheter $(\mathrm{N})$ & 134 & 207 & - & - \\
\hline IV catheter infection rate & $43(32.1 \%)$ & $30(14.5 \%)$ & $17.6 \%$ & $<.001$ \\
\hline Mean LOS (standard deviation) & $15.31(5.39)$ & $7.43(3.80)$ & $51.5 \%$ & $<.001$ \\
\hline IV device changing compliant to guidelines $(\mathrm{N})$ & 134 & 207 & & - \\
\hline Changing IV line & $0(0 \%)$ & $205(99 \%)$ & $99 \%$ & $<.001$ \\
\hline Changing IV bag & $120(89.1 \%)$ & $207(100 \%)$ & $10.9 \%$ & $<.001$ \\
\hline Changing IV catheter & $5(3.7 \%)$ & $203(98.1 \%)$ & $94.4 \%$ & $<.001$ \\
\hline Idle IV catheter & $41(30.6 \%)$ & $2(1 \%)$ & $29.6 \%$ & $<.001$ \\
\hline IV technique observed $(\mathrm{N})$ & 53 & 150 & - & - \\
\hline Proper technique used & $23(43 \%)$ & $144(96 \%)$ & $53 \%$ & $<.001$ \\
\hline Nurses with IV Knowledge score $\geq 80 \%(\mathrm{~N})$ & 6 & 6 & - & - \\
\hline Percentage & $2(33 \%)$ & $6(100 \%)$ & $67 \%$ & .03 \\
\hline
\end{tabular}

The nursing practice compliance rates on IV device management according to WHO guideline also improved. The compliance rate of changing IV line significantly increased from $0 \%$ pre-intervention to $99 \%$ post-intervention $(p<.001)$; changing IV bag compliance significantly increased from $89.1 \%$ pre-intervention to $100 \%$ postintervention $(p<.001)$; changing IV catheter compli- ance increased from $3.7 \%$ pre-intervention to $98.1 \%$ postintervention $(p<.001)$, idle IV catheter decreased from $70.6 \%$ pre-intervention to $1 \%$ post-intervention $(p<.001)$; proper technique used increased from $43 \%$ pre-intervention to $96 \%$ post-intervention $(p<.001)$; the mean rank of staff on IV management knowledge score significantly increased from 3.5 pre-intervention to 9.5 post-intervention $(p=.004)$ 
(see Table 2).

Among the 341 patients in the pre- and post-intervention periods, 123 patients developed IV CRI and had an average LOS of 17.22 days $(S D=3.97)$; which was significantly higher than the LOS of 6.74 days $(S D=2.48)$ among the 218 patients without IV CRI, with $p<.001$ (see Table 3 ).

Table 3. Comparison of LOS in hospital between patients with and without IV CRI

\begin{tabular}{llll}
\hline & With IV CRI & Without IV CRI & p-value \\
\hline Sample N & 123 & 218 & - \\
Mean LOS (SD) & $17.22(3.97)$ & $6.74(2.48)$ & $<.001$ \\
\hline
\end{tabular}

\section{Discussion}

The results of the quality improvement project significantly increased the compliance rate of proper management of IV, reduced the unnecessary idle IV, increased the IV management knowledge of the nurses and, most importantly, decreased the rate of IV CRI as well as an association in reduced LOS in the neonatology unit. Apart from time investment and training the organization, the project did not incur financial cost to the hospital. Our project showed that by following the step-by-step SPS approach, quality improvement project can succeed without requiring significant investment from the hospital. The results of our study also showed patients with IV CRI have significantly longer LOS in hospital compare to patients without IV CRI, which is consistent with other published studies. ${ }^{[1,2]}$

The team identified a focused and manageable problem that was within their control, thus making the intervention possible. We chose to focus on one single issue to solve first allowing us to create visible success and thus securing buy-in from the staff. Setting an achievable and realistic objective was also important to the success of this project. Showing positive results encouraged and motivated staff to continue their effort. A detailed assessment of the magnitude and root cause allowed us to identify the gap in practice and to formulate a clear and tangible intervention.

The team presented the results of the assessment to the hospital senior management team at an early stage to gain their approval to assure institutional support for the changes. Additionally, we included physicians and nurses from the beginning of the project to ensure the project get the support from both the leadership and front line staff. Involving affected NICU staff in the problem solving process was proved to be important. Their inclusion from the assessment to the evaluation encouraged them to take real ownership of the project. As a result, the implementation of the new practice guidelines were not met with much resistance. Initially, some doctors and nurses were concerned about how the new protocol would affected availability of some medical supplies in the long term. The concerns were discussed with the finance department and the hospital administration who reassured us of their support and continued availability of supplies. By addressing their concerns, the doctors and nurses felt integrated in the project team as oppose to feeling ordered to follow the new system.

The team believed it was crucial to maintain open communication and provide feedback during the implementation of the project. Each month, the team communicated the project outcomes to the staff and department heads during staff meetings. It was explained to them how each person's individual contribution had brought the department closer to achieving its goal of reducing IV Catheter related infections. The team selected an intervention that required minimal cost; which was critical to the project's feasibility and sustainability. Apart from printing the guideline and training materials, all other needed equipment and supplies were available within the department or hospital at no additional cost.

Despite the success of the results, this project was not without limitations. The post-intervention period of this project was short, the sustainability of the initial success is not clear, further follow up is needed. The results of our study showed an association with reduction in hospital LOS, however, hospital LOS is affected by many factors, thus we cannot be certain that the reduction was due to our intervention. Also, the project did not utilize a case-control study design, we cannot eliminate confounding factors to any outcome or impact. The study was limited to a single department in a single hospital; results may differ in other settings.

By applying the step-by-step systematic strategic problem a solving method, a quality improvement project was designed and implemented to reduce the IV CRI rate and enhanced proper IV management practice without cost added to the hospital.

\section{ACKnOWledgements}

The authors would like to thank the Rwanda Ministry of Health for supporting the program. In addition, the project would not have been possible without the hard work and commitment of the neonatology staff at Kibogora district hospital. Authors would also like to acknowledge Geralyn Sue Prullage, Mageza Sanctus and Ntirenganya Schadrack for their precious collaboration and participation in this project.

\section{CONFLicts OF InTEREST Disclosure}

The authors declare no conflict of interest. This project did not receive any funding. 


\section{REFERENCES}

[1] Arnow PM, Quimosing EM, Beach M. Consequences of intravascular catheter sepsis. Clinical Inf. Diseases. 1993; 16: 778-84. PMid: 8329510. http://dx.doi.org/10.1093/clind/16.6.778

[2] Bakr AF. Intravenous lines related sepsis in newborn babies admitted to NICU in a developing country. J Trop paed. Dec 2003; 49(5): 295-297.

[3] Kibogora hospital report. Annually report on different activities performed in Kibogora Hospital. Data manager office. 2015.

[4] Soub HA, Estinoso W. Hospital-acquired candidaemia: experience from a developing country. Journal of Hospital Infection. 1997; 35(2): 141-7. http://dx.doi.org/10.1016/S0195-6701 (97 ) $90102-X$

[5] Munchkhof WJ. Intravenous catheter-associated staphylococcus aureus bacteraemia: a common problem that can be prevented. Internal Medicine Journal. 2005; 35: 315-318. PMid: 15892759. http://dx.doi.org/10.1111/j.1445-5994.2005.00848.x

[6] Schwamburger NT, Hancock RH, Chong $\mathrm{CH}$, et al. The rate of adverse events during IV conscious sedation. General dentistry. 2012; 60(5): 341-4.

[7] Mac Gillivray. The father of intravenous infusion therapy. Journal of infection prevention. 2009; 10(suppl.1): 3-6. http://dx.doi.org /10.1177/1757177409342141

[8] CDC. Guidelines for the Prevention of Intravascular Catheter-Related Infections. Morbidity and Mortality Weekly Report. Aug 2002. Available from: http://www.cdc.gov/mmwr/preview/mmwrhtm 1/rr5110a1.htm

[9] Haley RW, Culver DH, White JW, et al. The efficacy of infection surveillance and control programs in preventing nosocomial infections in US hospitals. American Journal of Epidemiology. 1985; 121(2): 182-205. PMid: 4014115.

[10] Paulson PR, Miller KM. Neonatal peripherally inserted central catheters: recommendations for prevention of insertion and post insertion complications. Neonatal Netw. 2008; 27: 245-57. PMid: 18697655. http://dx.doi.org/10.1891/0730-0832.27.4.2 45

[11] Abramczyk ML, Carvalho WB, Carvalho ES, et al. Nosocomial infection in a paediatric intensive care unit in a developing country. Brazilian Journal Infect Dis. Dec 2003; 7(6): 375-380. PMid: 14636476. http://dx.doi.org/10.1590/S1413-86702003000600004

[12] Barbut F, Pistone T, Guiguet M, et al. Complications due to peripheral venous catheterization, prospective study. Presse Med. 2003 Mar 15; 32(10): 450-6. PMid: 12733305.

[13] Schwab F, Geffers C, Bärwolff S, et al. Reducing neonatal nosocomial bloodstream infections through participation in a national surveillance system. J Hosp Infect. 2007; 65: 319-25. PMid: 17350730. http://dx.doi.org/10.1016/j.jhin.2006.12.020

[14] Nagata E, Brito AS, Matsuo T. Nosocomial infections in a neonatal intensive care unit: incidence and risk factors. Am J Infect Control. 2002; 30: 26-31. PMid: 11852413. http://dx.doi.org/10.10 $67 / \mathrm{mic} .2002 .119823$

[15] El-Din EMRS, El-Sokkary MMA, Bassiouny MR, et al. Epidemiology of Neonatal Sepsis and Implicated Pathogens: A Study from Egypt. Biomed Research International. 2014; 2015: 1-11. http://dx.doi.org/10.1155/2015/509484

[16] Rosenthal VD, Bijie H, Maki DG, et al. International Nosocomial Infection Control Consortium (INICC) report, data summary of 36 countries, for 2004-2009. Am J Infect Control. 2012; 40: 396-407. PMid: 21908073. http://dx.doi.org/10.1016/j.ajic. 2011 .05 .020

[17] NHS. North so merest, policy for peripheral venous cannulation November 2009.

[18] Curry S, Honeycutt M, Goins G, et al. Catheter-associated bloodstream infections in the NICU: getting to zero. Neonatal Netw. 2009; 28: 151-5. PMid: 19451076. http://dx.doi.org/10.1891/073 $0-0832.28 \cdot 3 \cdot 151$

[19] Frasca D, Dahyot-Fizelier C, Mimoz O. Prevention of central venous catheter-related infection in the intensive care unit. Crit Care. 2010; 14: 212. PMid: 20236456. http://dx.doi.org/10.1186/cc885 3

[20] WHO. Prevention of hospital-acquired infections A practical guide. 2002. $2^{\text {nd }}$ edition. Available from: www. who.int/csr/resources/publications/drugres ist/WHO_CDC_CRS_EP_2002_12/en/

[21] Dudeck MA, Horan TC, Peterson KD. National Healthcare Safety Network (NHSN) Report, Data Summary for 2009, Device associated Module. American Journal of Infection Control. 2011; 39: 349-67. http://dx.doi.org/10.1016/j.ajic.2011.04.011

[22] Mermel LA, Allon M, Bouza E, et al. Clinical practice guidelines for the diagnosis and management of intravascular catheterrelated infection: 2009 Update by the Infectious Diseases Society of America. Clin Infect Dis. 2009; 49: 1. PMid: 19489710. http://dx.doi.org/10.1086/599376

[23] Raad I, Hanna H, Maki D. Intravascular catheter-related infections: advances in diagnosis, prevention, and management. Lancet Infect Dis. 2007; 7: 645-57. http://dx.doi.org/10.1016/S1473-3 099 (07) 70235-9

[24] Zhang L, Sriprakash KS, McMillan D, et al. Microbiological pattern of arterial catheters in the intensive care unit. BMC Microbiol. 2010; 19(10): 266. PMid: 20955628. http://dx.doi.org/10.1186/1 471-2180-10-266

[25] Guembe M, Rodriguez-Creixems M, Sanchez-Carrillo C, et al. How many lumens should be cultured in the conservative diagnosis of catheter-related bloodstream infections? Clin Infectious Dis. 2010; 50(12): 1575-1579. PMid: 20455693. http://dx.doi.org/10. $1086 / 652766$

[26] Kotagal M, Lee P, Habiyakare C, et al. Improving quality in resource poor settings: observational study from rural Rwanda. BMJ. 2009 Oct 30; 339: 3488. PMid: 19880528. http://dx.doi.org/10.11 $36 / \mathrm{bmj}$. b3488

[27] Robinson S, Pawelzik V, Megentta A, et al. A case study: Applying quality improvement methods to reduce pre-operative length of stay in a resource-constrained setting in Rwanda. J Hosp Adm. 2015; 5(1): 41-47. http://dx.doi.org/10.5430/jha.v5n1p41

[28] Kmanzi J, Megentta A, Nsabiyumva W, et al. Improving Clinical Documentation through Monthly Audits in Butare Teaching Hospital, Rwanda. Journal of Service Science and Management. 2015; 8 : 860-867. http://dx.doi.org/10.4236/jssm. 2015.86086

[29] Byiringiro JC, Wong R, Davis C, et al. Applying quality improvement principles to improve emergency department overcrowding and flow in Rwanda: A case study. J Hosp Adm. 2015; 4(5): 47-51. http://dx.doi.org/10.5430/jha.v4n5p47

[30] Banaszak-Holl J, Nembhard IME, Taylor L, et al. Leadership and management: a framework for action. Shortell Kaluzny's Healthc Manag Organ Des Behav. 2011; 40-45. 